\title{
ENSINAR E APRENDER DE INSTRUTORES E DE ALUNOS MILITARES
}

\author{
Deise Becker Kirsch ${ }^{1}$ \\ Maria da Graça Nicoletti Mizukami²
}

\begin{abstract}
Resumo: A pesquisa teve como objetivo mapear as concepçóes teórico-práticas acerca da docência de instrutores e a visão de alunos sobre os processos de ensino e de aprendizagem no ensino superior militar. Os sujeitos do estudo foram três instrutores e 78 alunos do último ano do Curso de uma Academia Militar. A abordagem metodológica contemplou uma pesquisa descritiva-analítica, baseada em entrevistas semi-estruturadas e abertas e um questionário aplicado aos instrutores militares. Aos alunos militares foi aplicado apenas um questionário, em função do quantitativo de sujeitos. A partir da análise dos dados foi possível compreender que os instrutores militares têm uma formação específica na sua área muito consistente ao passo que não possuem preparação pedagógica para a docência, aprendendo a serem professores na prática em sala de aula. Os alunos militares, ao exporem suas concepçóes em torno dos processos de ensino e de aprendizagem, relatam a importância da interação em sala entre professor-aluno, da didática, bem como as características do melhor e do pior docente. Conclui-se que os processos de ensinar e de aprender em uma Academia Militar náo estão distantes do que ocorre no meio civil, sendo construçóes que ocorrem ao longo da vivência escolar e demanda trabalho, conhecimento e compromisso por parte do professor; atividade, estudo, dedicação e interesse por parte do aluno.
\end{abstract}

Palavras-chave: educação militar; ensino-aprendizagem; formação do instrutor; aluno militar.

\section{INSTRUCTORS AND MILITARY STUDENTS' TEACHING AND LEARNING}

Abstract: This research studied the way instructors and students conceive teaching and learning in a military educational institution. The subjects of the study were three instructors and seventy eight students in their last year in a military academy. Our resarch is both descriptive and analytical

1 Licenciada em Pedagogia. Mestrado e Doutorado em Educação. Professora EBTT, do Instituto Federal do Paraná/Campus Londrina.

2 Licenciada em Pedagogia. Mestrado e Doutorado em Educação. Professora titular pela Universidade Federal de São Carlos. Atualmente professora adjunto III na Universidade Presbiteriana Mackenzie. 
and consists of open and semi-structured interviews. We also used a questionnaire for the militar instructors. As there were too many students, they were given just the questionnaire. From thisstudy we could conclude that the militar instructors are not pedagogically prepared for the teaching profession although their education in their specific area is very consistent. They learn to be teachers as they teach. The military students report that interaction between teacher and pupil is very importante. They also describe the characteristics of the best and the worst teachers. We conclude that the teaching and learning process of a military institution is not very diferent from that of a civillian one. In both cases, the process is built in the daily routine of the school and demands a lot of effort, knowledge and dedication from the teacher; and it demands activity, study, dedication and interest on the student's part.

Keywords: military education; teaching-learning; instructor's formation; military student.

\section{Introduçáo}

O presente texto apresenta os resultados da pesquisa realizada em uma Academia Militar, instituição de ensino superior, e teve como objetivo mapear as especificidades do processo de ensino e de aprendizagem dos instrutores militares, no que diz respeito à concepção teórico-prática acerca da docência, e do processo de ensino e de aprendizagem dos alunos militares, chamados de cadetes.

Um dos fatores determinantes na escolha de realização dessa investigação foi a existência de poucos estudos nessa área e a possibilidade de acesso ao contexto militar, onde existem peculiaridades no processo educativo e que, certamente, difere das demais instituições do país.

Desse modo, os sujeitos da investigação foram três oficiais, formados pela Academia Militar, que ministravam aulas na Instituição referente às disciplinas Técnico-Especializadas. Além dos instrutores, tivemos como sujeitos 78 cadetes do quarto ano (último) do Curso.

Através desse estudo buscamos identificar quem é o instrutor militar, sua formação e saberes, o que faz em sala de aula, como visualiza seus alunos e, por fim, em que medida o instrutor pensa e repensa sobre sua própria prática docente. Com relação ao cadete, buscamos identificar sua visão do processo de ensinoaprendizagem, das características dos professores/instrutores, de que forma ele aprende e o que observa ser relevante para sua formação profissional (técnicacientífica).

Quanto à formação inicial dos instrutores, ela ocorreu numa Academia Militar, sendo que no currículo há conhecimentos da área de administração e conhecimentos específicos da carreira militar. Isso significa dizer que não engloba assuntos referentes às questões pedagógicas, didáticas ou mais especificamente sobre técnicas de ensino, mas exige que o oficial ministre aulas aos cadetes quando retorna à Instituição.

De acordo com Pimenta e Anastasiou (2011, p.107), isso ocorre em outras áreas de atuação profissional no qual os sujeitos são incumbidos da docência e também "não recebem qualquer orientação quanto a processos de planejamento, 
metodológicos ou avaliatórios nem sequer necessita realizar relatórios - momento em que poderia refletir sobre a própria ação [...]".

Além de não haver formação, nem pós-formação voltada para a área pedagógica, os instrutores não possuem uma formação científica voltada à construção de conhecimentos, à atividade de pesquisa, o que poderia colaborar nas suas atividades como docentes, visto que estamos tratando do nível de ensino superior.

A partir disso, precisamos compreender como esse ensino militar ocorre, de fato, na prática diária, não somente do ponto de vista da formação e docência pelo instrutor militar, mas também do processo de aprendizagem do seu aluno, o cadete, considerando que vive no regime de internato durante todo o curso e a educação é regida pelos princípios da hierarquia e da disciplina.

Ao chegar à Academia, os alunos passam por um período de adaptação. Esse período é denominado Estágio de Adaptação, que tem duração de aproximadamente cinco semanas. Segundo Ludwig (1998, p. 35-36) no estágio: “[...] os neófitos são instados a acatar os valores dominantes da corporação bélica: obediência, disciplina, hierarquia, lealdade, pontualidade, assiduidade etc., que ainda não estão devidamente sedimentados nos iniciantes [...]".

Para tanto, o estudo partiu de duas questões: Como os instrutores militares percebem o processo de ensino e de aprendizagem na Academia Militar, no que diz respeito à concepção teórico-prática acerca da docência?

Como os cadetes percebem o processo de ensino e de aprendizagem ao qual foram submetidos?

Esse trabalho foi desenvolvido a partir de uma abordagem qualitativa e quantitativa, de cunho descritivo-analítico, no qual foram utilizadas entrevistas semi-estruturadas e abertas com os instrutores e aplicação de um questionário. Para os cadetes foi utilizado apenas o questionário, considerando o quantitativo de sujeitos.

\section{Fundamentaçáo teórica}

Como estamos trabalhando formação docente, desenvolvimento profissional e processos de ensino e de aprendizagem numa escola militar, precisamos deixar clara a base teórica utilizada nesse contexto de ensino e de aprendizagem, uma vez que esta dará subsídios para compreender melhor esse espaço educativo e a atuação de seus profissionais.

De acordo com as Tendências Pedagógicas (LIBÂNEO, 1994), as características do ensino Tradicional e do Tecnicismo despontam como abordagens utilizadas no meio militar. O Tradicional aparece através da metodologia de ensino, na qual predominam a exposição e demonstração verbal da matéria, e através da relação professor-aluno, na qual se destaca a autoridade do professor diante da receptividade do aluno, o qual deve assimilar os conhecimentos. De acordo com Saviani (1986), o aspecto lógico, a transmissão do conhecimento, a exigência da 
disciplina em sala, o diretivismo pedagógico e o esforço do aluno, são elementos fundamentais na prática de ensino tradicional.

Com relação à Pedagogia Tecnicista, esta aparece "inspirada na teoria behaviorista da aprendizagem e na abordagem sistêmica do ensino" (LIBÂNEO, 1994, p.67) e o ensino comportamentalista "prevê a utilização de uma "engenharia" comportamental e social sofisticada para moldar os comportamentos sociais, tendo em vista que o homem é considerado um produto do meio e, portanto, é passível de ser manipulado e controlado" (BAQUIM, 2008, p. 53).

Com essa fundamentação, o tecnicismo ganha o espaço no meio militar, pois está diretamente ligado à objetivação e operacionalização das atividades, inclusive no ensino, para o ensino. Dentro desse contexto, os conteúdos, que são informações ordenadas numa sequência lógica e psicológica, devem ser transmitidos pelo professor, recebidos e fixados pelos alunos.

Nessa perspectiva:

o sistema de instrução se compõe das seguintes etapas: a) especificação dos objetivos instrucionais operacionalizados; b) avaliação prévia dos alunos para estabelecer pré-requisitos para alcançar os objetivos; c) ensino ou organização das experiências de aprendizagem; d) avaliação dos alunos relativa ao que se propôs nos objetivos iniciais (LIBÂNEO, 1994, p.68).

Todo esse arranjo organizacional tem elevada importância no ensino militar e, além disso, nesse espaço educacional o

[...] funcionamento eficiente e eficaz implica a utilização de retroprojetores, na infindável e constrangedora listagem de verbos adequados para explicitar os objetivos gerais e específicos das diferentes disciplinas, na explicitação da atividade pedagógica toda clarificada por organogramas e cronogramas, por meio de módulos instrucionais, na instrução programada, na obrigatoriedade e no controle de uma determinada quantidade de avaliações dadas pelo professor. Tudo isso desemboca na burocratização do planejamento e da ação pedagógica (ARAÚJO, 2011, p.20).

Sendo assim, qual é o espaço da docência? Como podemos discuti-la nesse contexto? Podemos afirmar, inicialmente, que ela, ao ocorrer na escola, é "construída com base na realidade da instituição educativa concreta e seus determinantes" (VEIGA, 2010, p.19). Considerando o lócus de ensino e de aprendizagem, podemos fazer referência ao trabalho do professor:

[...] a docência se realiza segundo um certo processo do qual provêm determinados resultados. Organização, objetivos, conhecimento e tecnologias, objetos, processos e resultados constituem, consequentemente, os componentes da docência entendida como trabalho (TARDIF; LESSARD, 2009, p.39).

Para isso, precisamos ter a clareza de que a atividade docente não advém e está estritamente ligada ao talento, ao dom, mas sim compõe o universo das demais formas de trabalho humano (TARDIF; LESSARD, 2009). É por isso que destacamos a docência como profissão e que necessita que o professor adquira 
conhecimentos específicos de sua disciplina, mas, acima de tudo, possua também conhecimentos didático-pedagógicos pertinentes ao fazer docente.

Isso nos permite fazer referência ao trabalho docente como ação racionalizada, pelo fato de ter em si uma eficiência na organização e estar ligado com uma técnica, porém não com uma mera tecnicidade (TARDIF; LESSARD, 2009). Isso significa dizer que a atividade do professor não é a execução de uma receita, significa que ele precisa ter flexibilidade, ter condições de mobilizar os diferentes saberes para distintas e inesperadas situações em sala de aula e mesmo fora dela, no sentido de colocar em movimento o saber planejado, organizado e de domínio do professor, podendo este sofrer ou não alterações.

Desse modo, discutir os aspectos que envolvem a profissão docente requer pensarmos que esta abrange pessoas, as quais são a "matéria-prima" deste trabalho interativo, mas mais que isso, o trabalho desenvolvido é "com, sobre e para" os seres humanos (TARDIF; LESSARD, 2009). Por isso, a docência requer conhecimentos específicos, diferenciados para o "objeto humano", pois o trabalho docente a ser desenvolvido, não é o mesmo trabalho material, em que um homem irá exercer para a transformação de um objetivo físico, por exemplo.

Como os autores Tardif e Lessard (2009) colocam, o professor vai exercer tanto um trabalho cognitivo, quanto um trabalho "sobre" o outro. O trabalho cognitivo faz referência à atividade de manusear, física e intelectualmente, com as informações/conhecimentos, tais como programas, disciplinas, matérias e livros, configurando assim um dos elementos centrais do trabalho docente. Já no trabalho "sobre" o outro, é importante considerar a questão do poder, do estar à frente de todos e conduzir o processo segundo suas ordens, além do fato de envolver a coletividade. A coletividade por sua vez, apresenta dois aspectos: a questão da igualdade no tratamento com os outros e o controle do grupo.

A igualdade refere-se ao fato de todos os alunos estarem num mesmo ambiente e a classe precisar ser tratada pelo professor de maneira igualitária, embora saibamos que cada discente possui características, estilos e ritmos de ser e de aprender diferentes. Lidar com isso não é tarefa fácil e exige habilidade e flexibilidade por parte do docente.

A questão do controle do grupo é sempre um desafio à prática pedagógica, visto que se faz necessário ser autoridade sem ser autoritário. Faz-se importante dominar a turma ao mesmo tempo em que se abre espaço para o diálogo, ou seja, ter o controle do grupo como forma de promover o ensino e a aprendizagem exige do professor diferentes práticas em sala de aula. Exige que ele esteja diante da turma para ensinar, orientar e mostrar caminhos aos alunos.

Em outro aspecto, segundo Feldmann et al. (2004, p.148-149):

é preciso, ainda, adotar um conceito de formação que contemple o desenvolvimento de habilidades como organizar, fundamentar e revisar a teoria, articulando esquemas práticos predominantes e os esquemas teóricos que os sustentam. 
Desse modo, a construção do ser professor compreende possuir base teórica consistente que dialogue com a prática pedagógica.

Entretanto, o que ocorre com os instrutores muitas vezes é que: “[...] sua passagem para docência ocorre "naturalmente"; dormem profissionais e [ou] pesquisadores e acordam professores" (PIMENTA; ANASTASIOU, 2011, p.104). Considerarmos isso não é uma questão de culpá-los por não ter formação e/ou conhecimento específico para a docência, mas é uma maneira de entender pelo que passam, como chegam à docência e como administram tal problemática em suas salas diante de seus alunos, além de verificar em que medida isso pode ser evitado para que o tornar-se professor seja um processo e não um choque.

Por isso é com referência às investigações de Shulman (2004) que Mizukami (2004) vem colaborar quando escreve sobre os conhecimentos que os professores precisam ter para ensinar. A base de conhecimento para o ensino é um dos modelos apresentados pela autora quando faz a leitura dos trabalhos de Shulman (2004): "consiste de um corpo de compreensões, conhecimentos, habilidades e disposições que são necessários para que o professor possa propiciar processos de ensinar e de aprender" (MIZUKAMI, 2004, p.38). Além disso, tal base é flexível e sofre modificações à medida que o docente, na sua profissionalização, vai se construindo.

No percurso dessa discussão, a base de conhecimento para o ensino também é definida como: "um conjunto codificado ou codificável de conhecimentos, habilidades, compreensão e tecnologia, ética e provisão, de responsabilidade coletiva" (SHULMAN, 2005, p.5).

Essa base de conhecimento para o ensino se caracteriza, portanto, por ser uma base intelectual, prática e normativa, tendo em vista a concepção de ensino como profissão (MIZUKAMI, 2004), ou seja, precisamos considerar que há características inerentes e necessárias à constituição do ser professor e, por isso, a necessidade de desvelá-las.

Em decorrência dessa base de conhecimento, Mizukami (2004) discute também as categorias que dela derivam e que podem ser explicitadas em três grandes grupos de conhecimentos: conhecimento de conteúdo específico, conhecimento pedagógico geral e conhecimento pedagógico do conteúdo.

O conhecimento de conteúdo específico se refere a uma área específica de conhecimento do docente, a matéria em si que ele ministra. Sem dúvida, tais saberes são apropriados pelos profissionais que exercem a docência, entretanto, ele não é suficiente para a concretização do ensino. Ele é um saber fundamental, mas sozinho não atende/contempla a base de conhecimento para o ensino.

3 Tradução livre da frase: "Un conjunto codificado o codificable de conocimientos, destrezas, comprensión y tecnologia, de ética y disposición, de responsabilidad colectiva." (SHULMAN, 2005, p.5). 
Tal conhecimento pode ser evidenciado, por exemplo, no campo dos saberes dos instrutores militares, visto que possuem, com grande domínio, este conhecimento específico de sua área profissional.

Já o conhecimento pedagógico geral, faz referência àqueles que envolvem as características dos alunos, o conhecimento do espaço educacional, o trabalho em sala de aula e interação professor-aluno, o conhecimento do currículo, de metas e propósitos educacionais (MIZUKAMI, 2004). Este, conforme coloca a autora, está relacionado aos processos de ensinar e aprender, ultrapassando o conhecimento específico da área.

Contudo, é o conhecimento pedagógico do conteúdo que damos ênfase nesse momento. Ele seria a junção do conhecimento específico com o conhecimento pedagógico e é construído pelo professor na medida em que ensina a matéria e qualifica suas ações em sala de aula, observa se o aluno está aprendendo, que estratégias e analogias utilizou para isso, por exemplo. Segundo Mizukami (2004, p.40): "É o único conhecimento pelo qual o professor pode estabelecer uma relação de protagonismo. É de sua autoria. É aprendido no exercício profissional, mas não prescinde dos outros tipos de conhecimentos que o professor aprende via cursos $[\ldots] "$.

Quando transpomos essa teoria acerca da docência para o contexto da formação do instrutor militar, podemos dizer que, por mais que ele não tenha tido uma formação para licenciatura, ele está em sala de aula, portanto, exercita a docência. A questão não pode ser outra: o que ele aprende nesse percurso? Eis que surge a necessidade e o desafio de investigar como o instrutor militar aprende esse conhecimento pedagógico do conteúdo.

Além da base de conhecimento para o ensino como elemento importante para a docência, é possível abordarmos também acerca do raciocínio pedagógico, sendo que o seu entendimento significa que nós podemos compreender como o professor aciona, relaciona e constrói seu conhecimento durante o processo de ensino e de aprendizagem (MIZUKAMI, 2004).

Segundo Shulman (2004), o ensino começa com a compreensão que o próprio professor tem do conteúdo a ser ensinado, passando por um raciocínio, o qual implica em várias etapas, sendo um movimento, até chegar na nova compreensão acerca da matéria e, esta compreensão enriquecida, revela a consolidação de novas aprendizagens (MIZUKAMI, 2004).

Sendo assim, fazem parte do raciocínio pedagógico: compreensão, transformação, instrução, avaliação, reflexão e nova compreensão.

A compreensão significa que todo ensino possui seus propósitos e estruturas da área de conhecimento e os professores precisam, além da compreensão especializada da disciplina que ministram, saber organizar diferentes maneiras para ensinar esse conhecimento, isso é um processo que o professor precisa realizar (MIZUKAMI, 2004). Se pudéssemos traduzir essa primeira etapa, colocaríamos em forma de uma questão: Como eu ensino o que sei? 
Nesse caminho os conteúdos a serem ensinados são transformados a fim de que o outro (o aluno) possa entender o que o professor já sabe (compreendeu), eis que se apresenta assim o segundo processo, de transformação, o qual envolve outros quatro subprocessos que, segundo Mizukami (2004, p.42) são:

Interpretação crítica. Implica análise crítica de textos e revisão de materiais instrucionais à luz das próprias concepções da matéria [...] Representação. [...] envolve o uso de um repertório representacional que inclui analogias, metáforas, exemplos, demonstrações, explicações, simulações, [...] capazes de construir pontes entre as compreensões do professor e as que se deseja que os alunos tenham. Seleção. Trata-se de um subprocesso que envolve escolha de como o processo de ensino e aprendizagem será desenvolvido [...] Adaptação $e$ consideração de características dos alunos. Esse último subprocesso envolve levar em consideração as concepções, preconcepções, concepções equivocadas, dificuldades, linguagem, cultura [...] de turmas, alunos e contextos específicos.

Uma questão que resumiria o processo de transformação: de que maneira(s) eu posso ensinar o que sei?

O terceiro processo, a instrução, será a prática do professor, como ele vai organizar e lidar com a classe, apresentar o conteúdo, desenvolver atividades de grupo ou individual, enfim, refere-se ao que é observado na aula do docente. Podemos colocar as seguintes perguntas: Como estou ensinando? O que estou fazendo para ensinar?

Já a avaliação, é um processo a ser desenvolvido tanto durante quanto depois da instrução, seja informal ou formalmente (MIZUKAMI, 2004). Uma representação em forma de questão: o que eu fiz e/ou poderia fazer em minha prática pedagógica? Esse processo de avaliação é fundamental e pode ser colocado ao lado do conhecimento pedagógico do conteúdo (SHULMAN, 2004).

A reflexão, penúltimo processo, "envolve a revisão e análise crítica do desempenho do professor [...] são processos reflexivos sobre a ação pedagógica" (MIZUKAMI, 2004, p.43). É nesse momento que o docente irá pensar, fazendo uma análise sobre suas experiências pedagógicas, o que pode encaminhá-lo ao último processo. Nesse momento, o professor analisa o ensino e a aprendizagem que ocorreu e reconstrói essa vivência (SHULMAN, 2004).

Podemos resumir a reflexão a partir da pergunta: o que eu fiz durante meu trabalho docente está de acordo/atingiu com as metas educacionais desejadas/ planejadas?

A nova compreensão surge então a partir do que já foi vivenciado pelo professor, dos processos anteriores, sendo que esta será "uma compreensão enriquecida dos propósitos, da matéria, do ensino, dos alunos, do próprio professor [...]" (MIZUKAMI, 2004, p.43).

Contudo, essa nova compreensão não ocorre automaticamente, ela será fruto do intenso processo de avaliação e reflexão (SHULMAN, 2004). Podemos perceber a importância dessa atividade para quem está ligado ao ensino. Ela elucida 
os caminhos para a qualificação das práticas pedagógicas e dá suporte para a análise dos processos de pensamento e ação dos instrutores em sala de aula.

Nesse percurso, é possível também fazermos inferência acerca da construção da identidade docente, a qual é contínua, ou seja, está em processo, não é finita, acabada, permite que o sujeito possa, ao vivenciar diferentes situações e nos distintos espaços que freqüenta e, ao realizar estudos e cursos, "reelaborar os saberes inicialmente tomados como verdades" (PIMENTA; ANASTASIOU, 2011, p. 113). Dessa maneira, o professor redimensiona seu conhecimento, contribuindo assim para o desenvolvimento pessoal, profissional e institucional.

Vale ressaltar o porquê de estarmos discutindo a identidade docente. Um primeiro ponto é que precisamos "da clareza e compreensão do eu-professor existente em cada um de nós” (PIMENTA; ANASTASIOU, 2011, p. 115) visto que só a partir disso é que podemos pensar na prática pedagógica/formação docente de ontem, hoje e o que queremos para amanhã. Sem saber o eu-professor, não temos como dar o primeiro passo na transformação e qualificação do ensinar e do aprender.

O segundo ponto diz respeito ao conhecimento de quem é o profissional da educação. Qual a origem de suas crenças e atitudes como docente, e é buscando da identidade dele (dos elementos que a compõe: características pessoais, profissionais, institucionais) que poderemos compreender seu comportamento e seu modo de agir como professor.

Não bastasse isso, Veiga (2011a) aponta em relação aos fundamentos em que a docência, na maioria das vezes, está baseada e que está diretamente ligada ao contexto de nossa investigação, a racionalidade técnica, ou seja,

a docência na Educação Superior foi influenciada pela concepção disciplinar e fragmentada que separa teoria da prática [...] isso leva os professores a uma dependência do conhecimento do campo científico para a condução de sua prática docente, o que contribui para a caracterização da docência calcada na transmissão do conhecimento existente (VEIGA, 2011a, p.456).

Isso explica a maneira como a educação se organiza, baseando-se apenas na transmissão de conteúdos. E essa é uma herança muito forte, que ainda não conseguimos transformar, tanto os modos de ser como de fazer dos seus profissionais.

Tal situação encaminha para uma prática do instrutor militar fundamentada no conhecimento científico em detrimento do saber pedagógico, fortalecendo a ideia de que quem sabe ensinar é quem domina o saber específico, como já estamos tratando ao longo desse trabalho.

Conforme Zabala (1998) essa concepção surge em função da descrença em relação aos conhecimentos pedagógicos e sua validade, em função da desconfiança no que se refere à falta de rigor nas investigações do campo educacional, ou seja, o medo da mudança com a inserção de novas formas de conduzir uma turma em aula advindo dos estudos, principalmente, da psicologia da aprendizagem. Isso 
repercutiu, e ainda repercute, “[...] na prática, a manutenção de formas tradicionais de atuação na aula" (ZABALA, 1998, p.33).

Isto posto, se pensarmos em termos das concepções educacionais no meio militar, prevalece o conceito de ensino instituído e, além disso, o termo instrução é forte, em especial para as disciplinas da área específica.

É por isso que a Didática se preocupa com o trabalho docente, que é modalidade do trabalho pedagógico, e que representa a prática do ensinar (LIBÂNEO, 1994), na qual existe a necessidade do saber fazer fundamentado para que a instrução e a educação ocorram com êxito. Para tanto, "a Didática se caracteriza como mediação entre as bases teórico-científicas da educação escolar e a prática docente. Ela opera como que uma ponte entre o "o quê" e o "como" do processo pedagógico escolar" (LIBÂNEO, 1994, p.28).

Dentro dos aspectos didáticos, encontramos a comunicação. Apesar de parecer um elemento corriqueiro e que dominamos, muitas vezes deixamos de dar a devida atenção para o processo comunicativo no ensino e na aprendizagem. Dentro desse processo temos a comunicação verbal e não verbal. Para a verbal, destacamos a linguagem oral e/ou escrita; com relação a não verbal, que aparentemente é menos utilizada, refere-se aos desenhos, sons, movimentos, expressões etc.

Essas formas de comunicar também expressam emoções e estas são importantes no processo de aprendizagem. Segundo Gil (2009) o professor pode se utilizar dessa comunicação não verbal para que o aluno aprenda determinados conteúdos se enfatizar a colocação e volume da vOz, mudar as expressões corporais, pois a capacidade de retenção dos sujeitos é muito maior quando visualizam do que quando escutam.

Por esses motivos podemos dizer que, na docência, não somente a linguagem oral e escrita tem fundamental importância, mas acima de tudo essa linguagem não verbal. Além disso, quantas vezes professores comunicam muitas coisas aos alunos sem perceberem, justamente por não estarem utilizando a linguagem oral e sim corporal. Também, podemos pensar nas inúmeras vezes que os alunos se confundem, ou são confundidos pelo professor, quando este expressa oralmente uma informação e transmite com gestos outra.

No ambiente militar isso pode ser um fator impactante. Muitas vezes o instrutor não fala para o cadete, mas sua postura e suas expressões podem incentivar uma relação positiva professor-aluno ou, ao contrário, barrar uma interação saudável.

É preciso assim, encarar a comunicação como elemento central para a prática docente. Outro exemplo diz respeito às explicações orais dada pelo instrutor durante a explanação do conteúdo. Às vezes, faz-se necessário explicar de maneiras diferentes para que todos os alunos consigam entender, pois nem sempre a linguagem utilizada pelo instrutor consegue atingir o entendimento por parte de todos os cadetes. 
De acordo com Santos (2008) é nesse aspecto da comunicação que os professores se distinguem uns dos outros, tendo em vista a trajetória pessoal/experiencial que tiveram e que influencia no conhecimento prático e, consequentemente, na repercussão desses nas situações de aprendizagem. "Os professores não explicam um conceito do mesmo modo, não seguem percursos idênticos na resolução de um problema, não dão as mesmas respostas em situações iguais, uma vez que as individualizam" (SANTOS, 2008, p.64).

Pensando na aprendizagem do cadete isso pode refletir de maneira muito positiva, pois, considerando as diferenças individuais na forma de aprender, os distintos modos de comunicação em sala de aula por parte do docente podem contribuir no entendimento do conteúdo pelo aluno.

Adentramos, desse modo, no percurso da prática de instrução em si, ou seja, do processo de ensino. Para Libâneo (1994, p.54):

podemos definir o processo de ensino como uma sequência de atividades do professor e dos alunos, tendo em vista a assimilação de conhecimentos e desenvolvimento de habilidades, através dos quais os alunos aprimoram capacidades cognitivas [...]

Para tanto, nesse processo a finalidade "é proporcionar aos alunos os meios para que assimilem ativamente os conhecimentos [e com isso referenciar que] a natureza do trabalho docente é a mediação da relação cognoscitiva entre o aluno e as matérias de ensino" (LIBÂNEO, 1994, p.54).

Nesse envolvimento professor-conteúdo-aluno, é relevante que destaquemos o processo interativo que ocorre em sala de aula. Por mais que saibamos que há muitas aulas expositivas no ambiente militar, devido sua própria estrutura organizacional, precisamos avançar e demonstrar, dentro da ótica de construção do conhecimento, as relações necessárias para que envolvam os professores, os alunos e a matéria a ser ministrada, distinguindo assim os papéis de cada um no processo.

Para tanto, segundo Zabala (1998, p.91)

parece mais adequado pensar numa organização que favoreça as interações em diferentes níveis: em relação ao grupo-classe, quando de uma exposição; em relação aos grupos de alunos, quando a tarefa o requeira ou o permita; interações individuais que permitam ajudar os alunos de forma mais específica; etc.

Com essa maneira de pensar estamos trabalhando com uma abordagem de ensino que vai além da mera transmissão do conhecimento. Acreditamos que parte do sucesso da aprendizagem do cadete encontra-se no fazer docente, no como a instrução é ministrada e, para além disso, quais são os conhecimentos apropriados pelo instrutor além daqueles no conteúdo específico da disciplina. Porque a bagagem de conhecimento pedagógico que o professor possui influi no seu trabalho de mediação do conteúdo abordado com os alunos. 


\section{A pesquisa realizada no espaço militar}

A partir da análise das entrevistas semi-estruturadas e abertas com os instrutores militares foi possível o levantamento de eixos temáticos acerca dos quais podemos ir traçando as características da formação e da prática docente deles. Foram estabelecidos quatro eixos temáticos, abaixo denominados e descritos:

"A vida escolar: o início da trajetória e suas experiências", é o eixo que apresentou o ingresso dos instrutores no meio militar e suas experiências como alunos, quais características consideraram acerca dos melhores, dos piores e dos professores ideais. Eles expuseram que, quando alunos, tiveram a maioria de suas aulas expositivas, nas quais tinham medo de fazer perguntas. Eles também lembraram das aulas em que podiam trabalhar em grupo e o quanto essa interação era importante. Além disso, consideram fundamental o professor qualificado, que saiba transmitir determinado conteúdo e que tal conteúdo seja relevante para o aluno possa utilizá-lo na prática.

"Práticas dos instrutores: descrevendo sobre suas aulas e seus alunos", tal eixo refletiu o perfil das disciplinas ministradas pelos instrutores, a visão deles sobre as aulas que os cadetes gostam ou não e o porquê, além de descreverem os conteúdos com os quais tiveram mais ou menos facilidade de ministrar em sala de aula. Os instrutores destacam que as aulas maçantes, com muito conteúdo teórico, são as que os alunos menos gostam e, as que os cadetes mais gostam, são aquelas práticas, interativas e/ou com desafios para serem resolvidos por eles.

"O entendimento do instrutor em relação a conhecimentos didáticopedagógicos", trouxe a compreensão do instrutor sobre seu aluno: como ele sabe que o cadete aprendeu um determinado conteúdo e como organiza sua aula. A maioria dos instrutores visualiza que o cadete aprendeu quando ele consegue explicar sozinho o conteúdo ministrado em aula. O instrutor também explicou as diferentes formas de planejar e ministrar sua aula, de acordo com a matéria abordada.

"Aprendizagem da docência a partir da prática" é o eixo que revelou a aprendizagem propriamente dita da docência pelo instrutor militar, relatando suas dificuldades, erros e acertos, como o próprio instrutor soube que aprendeu algo e a necessidade de aprender mais sobre conhecimentos didático-pedagógicos. Para eles, aprender a ser professor ocorreu por tentativas e erros, por uma mescla de aprendizagens em cursos da sua área e pela própria experiência profissional que não a docência.

Esses resultados, em especial o último eixo temático, estão balizados nas discussões sobre o aprender a ser professor e a identidade docente, cunhado por Pimenta e Anastasiou (2011); também, aparecem nitidamente quando abordamos a base de conhecimento para o ensino, revelado por Shulman (2004) e nos estudos de Mizukami et al. (2002, 2004).

Com relação ao questionário aplicado aos cadetes, foram distribuídos 118 questionários, sendo que retornaram respondidos 78 questionários. Esse resultado 
pode ser considerado positivo, pois apesar de estarem prestes a se formar na época da pesquisa, aproximadamente duas semanas antes da conclusão do curso, com muitos afazeres e ajustes para a formatura, os cadetes responderam com bastante seriedade todas questões.

Como são muitas e distintas as respostas dos cadetes no questionário, optamos, nesse momento, em limitar e apresentar, para cada uma das questões, apenas as respostas que tiveram o maior número de cadetes respondendo.

Sobre o ensinar: pelas próprias características da instituição militar que os cadetes vivenciam diariamente, quando perguntado o que consideravam ser o ensinar, a maioria trouxe a conceituação de transmissão de conteúdo, passar e repassar conhecimentos, conforme discutido na literatura a partir de Libâneo (1994) e Saviani (1986). Sobre o aprender: a maioria respondeu que é absorver, adquirir, compreender; outros cadetes, porém, escreveram que aprender é simplesmente tomar ciência, receber, algo que se acumula, conforme a ideia do ensino tradicional (LIBÂNEO, 1994).

Quanto à questão de como o cadete sabe que aprendeu, grande parte deles respondeu que é quando realiza procedimentos, resolve questões sozinho, aplica o conhecimento, sendo 44\%. Eles deram os seguintes exemplos: responder perguntas sem usar o livro para consultar; preencher o plano de atividades militares sem auxílio; apresentar a monografia; etc.

Dentre as características de um professor/instrutor ideal para os cadetes, está aquela em que o instrutor sabe transmitir a matéria e tenha didática. Isso significa dizer que o professor precisa ter o conhecimento específico do assunto e, assim, saber colocá-lo em ação em prol do processo de ensinar e de aprender. Podemos expressar, teoricamente, que o docente precisa desenvolver o conhecimento pedagógico do conteúdo (SHULMAN, 2004).

O melhor professor/instrutor, na visão dos cadetes, é o que interage com os alunos buscando sua participação. Segundo eles, o instrutor ideal é aquele que proporciona a interação entre professor e alunos e entre os próprios alunos. E, nesse aspecto, a comunicação é imprescindível, como já apontado por Gil (2009).

$\mathrm{O}$ pior professor/instrutor, na maioria das respostas, apontou para o que fica apenas lendo, passando slides, ou seja, um professor apenas falando, de maneira expositiva, cansativa (LIBÂNEO, 1994). Apesar de os recursos audiovisuais terem vindo para complementar e auxiliar as aulas, palestras, reuniões etc., o que percebemos foi a utilização deles indevidamente, como fonte principal numa aula e os professores sendo caracterizados como leitores de slides.

Sobre a aula ideal, a maioria dos cadetes revelou que precisa haver interação professor-aluno, sendo dinâmica e onde todos possam participar. Com isso, mais uma vez, eles demonstraram a importância do movimento em uma aula, da possibilidade de intervir, de um professor que dê esse espaço ao aluno.

Quanto à aula que mais gostam, apareceu aquela em que o conhecimento possa ser utilizado na prática. Os cadetes justificaram que se torna mais fácil a 
assimilação do conhecimento e eles têm a sensação de estar "fazendo alguma coisa", além de poder ver a aplicação da teoria. Isso reflete positivamente no que consideram relevante para sua formação profissional.

Quanto à aula que menos gostam, consideraram a expositiva, de cunho teórico. Os cadetes justificaram que é uma técnica cansativa, desinteressante, monótona e o professor, muitas vezes, fica apenas falando e passando slides. Ainda, segundo os alunos, é uma técnica que dá muito sono e não há espaço para tirar dúvidas. Novamente podemos considerar os apontamentos de Libâneo (1994) e Saviani (1986) quando remetem ao modelo de ensino tradicional/tecnicista nesses espaços escolares e que, na maioria das vezes, não é motivador.

Quanto à importância da relação professor/instrutor-aluno, um número considerável escreveu que a base do relacionamento professor-aluno é o respeito mútuo, o que acreditamos bastante pertinente e relevante no processo de ensinar e de aprender. Segundo 38 cadetes quando o aluno se sente à vontade com o instrutor o aprendizado fica mais fácil; quando há o respeito mútuo, há o respeito à autoridade do professor e as dificuldades do aluno, sendo que dessa forma, ambos são valorizados em seus papéis na sala de aula.

De acordo com os cadetes, as aulas em que mais e melhor aprendem são aquelas aulas dinâmicas, debatidas, discutidas, dialogada, com exemplos. Ou seja, os cadetes também não aceitam a condição de sujeitos passivos em sala, meros receptores de conhecimento, e sim desejam estarem envolvidos no ensinar e no aprender, tendo a possibilidade de se expressarem, ao mesmo tempo em que podem ouvir os exemplos dados pelos mestres.

Isto posto, podemos, na sequência, entrelaçar essas respostas dos cadetes e dos instrutores que, embora apresentadas de forma sintética, representam muito de seus processos de ensino e de aprendizagem.

\section{Interligando os dados do estudo}

A partir do mapeamento das especificidades do processo de ensino e de aprendizagem dos instrutores militares, no que diz respeito à concepção teóricoprática acerca da docência, e do processo de ensino e de aprendizagem dos cadetes de uma Academia Militar, podemos verificar onde essas duas "facetas" se cruzam, se encontram ou mesmo se afastam.

Para iniciar, podemos destacar que algumas perguntas realizadas para os instrutores também foram feitas aos cadetes. O que impressiona são os muitos pontos em comum existentes, sobre os quais vamos discutir abaixo.

Quando perguntado ao instrutor e aos cadetes as características de melhor professor, ambos evidenciaram que é aquele que motiva a turma, dá uma aula descontraída, faz com que haja interação professor-aluno e demonstra a necessidade de aprender tal conteúdo.

Desse modo, o melhor professor é aquele que "agita" a turma, que não quer uma sala apenas de ouvintes, está realmente disposto a se envolver e envolver os 
alunos no processo educativo. A visão do instrutor e do cadete está na mesma direção e destacamos sua importância, pois, apesar de inseridos num contexto militar, com base na hierarquia e na disciplina, no que concerne às relações em sala de aula, com os outros e com o conhecimento, é importante que haja flexibilidade de ação, sem desconsiderar a autoridade docente, mas com a finalidade de crescimento e desenvolvimento intelectual a partir de uma postura do instrutor que permita que o aluno se aproxime.

Nesse sentido, podemos abordar a questão da autoridade na sala de aula que, segundo Tardif (2002, p.139), "no tocante ao professor, a autoridade reside no 'respeito' que ele é capaz de impor aos seus alunos, sem coerção", ou seja, sem usar do poder, do posto que ocupa como na instituição militar, por exemplo, para que seja respeitado, e sim seja respeitado como autoridade, sem jamais deixar de manter o diálogo e a boa relação com a turma.

Outra pergunta realizada tanto para o instrutor quanto para o cadete foi em relação ao pior professor. Eles foram unânimes em dizer que uma das características é aquele professor que lê na aula, seja slide, seja apostila. Sendo assim, demonstraram suas experiências negativas nas aulas realizadas com um professor leitor de slides, refutando, assim, esse comportamento docente. Nesse sentido é importante pensarmos o quão cuidadoso precisa ser o trabalho docente, visto que é um trabalho "com, sobre e para" os seres humanos, conforme apontado por Tardif e Lessard (2009).

Em contrapartida, o professor ideal na visão dos sujeitos é aquele que domina o assunto e demonstra para a turma o quanto é fundamental esse saber para sua formação profissional. Considerando isso, para os sujeitos, o professor ideal é aquele que traz sua experiência para a sala de aula e mostra a aplicabilidade de muitos temas estudados. As características do professor ideal estão muito próximas das características do melhor professor e se entrelaçam com a literatura quando explicitamos a necessidade da base de conhecimento para o ensino (SHULMAN, 2004; MIZUKAMI et al., 2002; MIZUKAMI, 2004).

Convém fazer referência que os instrutores e cadetes não fizeram uma lista de característica/competências acerca do professor ideal, não expuseram o ideal como perfeição, mas muito próximo do que já visualizaram como alunos, do que foi possível ser executado em sala de aula. Isso porque se formos buscar na literatura de formação docente, o ideal, o conceito de novo professor, preenche muitas e muitas folhas de discussão, como nos estudos realizados por Mizukami et al. (2002).

Dentre os outros pontos abordados destacamos a resposta que instrutores deram em relação à aula que os cadetes mais gostam e as respostas que os cadetes deram quando deveriam dizer acerca da aula que mais gostam: aula dinâmica, participação de todos, ilustrada, sem leitura, todos interagindo e buscando o conhecimento.

Isso vai ao encontro do que já estávamos discutindo, quando colocamos a relevância de um processo de ensino e de aprendizagem que coloque os sujeitos 
como ativos e envolvidos no trabalho em aula e que o docente não é mero transmissor de conhecimentos e o aluno receptor de conteúdos.

Nessa perspectiva, considerando a concepção construtivista, a partir da qual acreditamos que o processo de aprendizagem, de fato, ocorra, segundo Zabala (1998, p.37):

\begin{abstract}
Nesta explicação, pressupõe-se que nossa estrutura cognitiva está configurada por uma rede de esquemas de conhecimento. Estes esquemas se definem como as representações que uma pessoa possui, num momento dado de sua existência, sobre algum objeto de conhecimento. Ao longo da vida, estes esquemas são revisados, modificados, tornam-se mais complexos e adaptados à realidade, mais rico em relações. A natureza dos esquemas de conhecimento de um aluno depende do seu nível de desenvolvimento e dos conhecimentos prévios que pôde construir; a situação de aprendizagem pode ser concebida como um processo de comparação, de revisão e de construção de esquemas de conhecimento sobre os conteúdos escolares.
\end{abstract}

Segundo o autor, não basta que o aluno esteja diante dos conteúdos para aprender, é preciso que ele estabeleça relações entre seus esquemas já existentes e o novo conhecimento e, se isso ocorrer, pode-se estar produzindo a "aprendizagem significativa" (ZABALA, 1998, p. 37).

Nesse percurso é evidenciado, tanto por instrutores quanto por cadetes, o quanto são válidas as relações entre instrutor-aluno e aluno-aluno. De alguma maneira deixam isso claro em suas respostas. Nessa dinâmica de se comunicar é que o conteúdo é compreendido, os professores se aproximam dos cadetes e contam suas experiências. Os cadetes, por sua vez visualizam seu futuro profissional. O aluno é respeitado e ouvido, sem deixar o instrutor de controlar e orientar a turma.

O processo interativo na aula, portanto, é fundamental, pois possibilita a construção conjunta dos conhecimentos, tanto considerando uma participação do aluno orientada pelo professor, quanto da construção compartilhada de conhecimentos quando os alunos estão interagindo (ZABALA, 1998).

Mas não é somente dessa relação que a aprendizagem frutifica. Muitas vezes nas falas dos cadetes aparece a importância de haver a diversificação das técnicas/ estratégias de ensino no processo de ensinar e de aprender. A justificativa vem de que manter um único tipo de aula no decorrer da disciplina não é prazeroso nem motivador. Sobre essa questão Veiga (2011b, p. 113) coloca:

Pode-se afirmar que muitos estudantes sugerem: a diversificação das técnicas de ensino e a redução do número de seminários, que são importantes desde que bem planejados e bem orientados pelos professores. Embora seja possível desenvolver toda uma disciplina, ou curso, mediante a técnica de seminário [por exemplo], especialmente no caso da pós-graduação, na graduação e no ensino médio deve-se atender o princípio da variedade, ou seja, o emprego variado de técnicas de ensino, de recursos materiais e de abordagens.

Essa citação deixa claro que apenas a aula expositiva não é suficiente para as necessidades de aprendizagem dos alunos. Torna-se relevante usar técnicas e/ou estratégias de ensino pertinentes a cada conteúdo trabalhado. Além disso, podemos 
dizer que, ao diversificar essas técnicas e/ou estratégias, estamos auxiliando no processo de aprendizagem dos alunos, quando se tenta atingir os diferentes sujeitos que estão em sala de aula.

Outro dado relevante é que, tanto na pergunta aos instrutores quanto aos cadetes, sobre como eles sabem que aprenderam algo, a maioria respondeu que é quando consegue realizar as atividades sozinhos, sem precisar da ajuda de outros. Nesse sentido, quando a literatura aborda as situações de aprendizagem, referese justamente à necessidade da autonomia do aluno diante dos conhecimentos, a partir das situações que vivencia:

Numa primeira fase, os alunos seguirão os modelos ou as diferentes ações
propostas pelos professores, com uma ajuda intensa por parte deste. Nas
fases seguintes será retirada esta ajuda de maneira progressiva, usando pouco
a pouco os conteúdos que ainda são utilizados pelo professor ou professora
e assegurando a passagem progressiva de competências do nível interpessoal
inicial, quando todos trabalham juntos, para o nível intrapessoal, quer dizer,
quando o aluno é capaz de utilizá-las de forma autônoma (ZABALA, 1998,
p. 102).

Por isso quando os sujeitos apontam que sabem que aprenderam algo quando conseguem fazer sozinhos, é justamente o processo de aprendizagem se configurando e, cada um, no seu ritmo e tempo, vai alcançando os objetivos propostos no ensino.

$\mathrm{Na}$ maioria das respostas dos cadetes aparece também a necessidade da aplicabilidade do assunto dado em aula. Infelizmente, observamos esse ponto no transcorrer da análise dos dados, dessa necessidade de aplicar o conteúdo, podendo ser um resquício das concepções inerentes à abordagem tecnicista, advinda das décadas de 60 e 70 (LIBÂNEO, 1994). Essa ideia está muito próxima do ensino técnico profissional, o qual se volta na formação do sujeito apto ao mercado de trabalho, não importando muito o desenvolvimento de pensamento crítico e a produção de conhecimento.

Os cadetes também expuseram muitas vezes acerca da aula interessante, significativa quando tiver interação, for dinâmica, debatida, dialogada. Podemos verificar que eles querem aprender, que estão dispostos a se envolver em sala, apesar de possuir uma rotina exaustiva.

Por mais que os alunos às vezes estejam cansados e/ou sonolentos, no momento em que se propõe em sala de aula uma dinâmica que dê oportunidade dele falar, instigue sua curiosidade, gere questionamentos, com certeza ele vai se envolver, cansado ou não, pois aquilo passa a "atingir" esse cadete de alguma maneira e parece-nos que é isso que fica claro nas suas próprias afirmações.

Com relação à formação do instrutor militar e o processo de ensinar, podemos concluir que: o instrutor não obteve uma formação específica para esse fim; utiliza-se de modelos, materiais, de vivências que teve como aluno; tem como referência para suas aulas os exemplos positivos e negativos que o marcaram durante a vida estudantil, vindo ao encontro das pesquisas de Mizukami et al. (2002); e, 
infelizmente, na visão do instrutor, é muito forte o ensino como sinônimo de transmissão, embora não se resuma a isso quando ele descreve com detalhes, ao longo da entrevista/questionário, suas práticas e concepções acerca do ensinar e do aprender.

Desse modo, podemos referenciar acerca da identidade do instrutor militar e, conforme Pimenta e Anastasiou (2011), os três elementos que compõem a construção da identidade docente foram evidenciados na pesquisa: a adesão, quando o instrutor assume a prática para si, apropriando-se dos princípios e valores; a ação, quando a partir de sua trajetória atua em sala; e, embora incipiente, a autoconsciência, aparece no momento em que o instrutor pensa e repensa sobre o que fez e faz em sala de aula. Apesar de não existir um processo reflexivo, o instrutor caminha nesse sentido quando se afasta da "fazeção" em sala.

Assim, podemos escrever sobre algumas impressões sobre o trabalho com os instrutores militares e que tratam acerca do ensino, de suas práticas, o que repercute na aprendizagem dos cadetes: em nenhum momento eles tiveram receio de escrever ou falar o que pensavam; colocaram-se sempre como sujeitos que querem se expressar de maneira espontânea em sala e consideram isso importante para as relações em aula com os cadetes; eles próprios condenam práticas autoritárias e professor leitor de slides; e, por fim, eles também consideram que uma aula meramente expositiva não motiva, causa sono e desânimo.

Com isso podemos observar como as falas/escritos dos instrutores, de alguma maneira, estiveram sempre inclinadas na direção de como eles se veem instrutores e como se sentem ou se sentiam como alunos. Eles jamais esquecem o que passaram como cadetes e suas falas/escritos explicitam isso. Eles aproveitam essa experiência tanto para construir sua prática quanto para aperfeiçoá-la.

Podemos dizer que esse estudo não tem um ponto final, pois processos de ensinar e de aprender, com o tempo, as diferentes pessoas, o contexto, tudo vai se transformando, aperfeiçoando, incorporando novas ideias e valores. Apesar disso, pudemos realizar, com a colaboração dos sujeitos quando "abriram suas mentes" e expuseram suas concepções, o mapeamento e a análise de um lócus de educação ímpar e rico em experiências profissionais.

Portanto, é importante para a Instituição um tempo para amadurecer novas ideias acerca do instrutor como docente e visualizar o quanto é importante valorizar os profissionais do ensino, dar apoio àqueles oficiais que gostam de dar aulas e não fazem isso para cumprir uma escala.

4 Grifo nosso.

5 Grifo nosso. 


\section{Consideraçóes finais}

Em relação ao instrutor militar, este demonstrou ao longo da pesquisa todo seu comprometimento com a docência, seu envolvimento com o trabalho e o estudo. Para tanto, o instrutor, além de obrigações e atividades específicas militares, precisa ser incentivado a permanecer nos caminhos da instrução, pois sua prática diária o aperfeiçoa e ele pode contribuir significativamente para o processo de ensino e de aprendizagem.

O cadete é um sujeito que também traz para a escola militar muito conhecimento e experiências que podem ser trabalhados na aprendizagem de novos conteúdos, enriquecendo assim o espaço da sala de aula. Ele é um aluno diferenciado dos que vivem no meio civil justamente por ingressar e permanecer todo Curso em regime de internato e tendo obrigações militares a cumprir mas, assim como os demais do meio civil, tem curiosidade, gosto por desafios e se mostra disposto a participar, de maneira ativa, na construção das aulas.

Assim, podemos concluir que os processos de ensinar e de aprender de instrutores e de cadetes são construções compartilhadas (ZABALA, 1998) que ocorrem ao longo da vivência escolar, em qualquer um dos níveis que o sujeito estiver inserido; demanda trabalho, conhecimento e compromisso por parte do instrutor; atividade, dedicação e interesse por parte do aluno. Se houver o entrelaçamento dos processos de ensino e de aprendizagem, certamente alcançaremos êxito nas atividades escolares e no desenvolvimento/crescimento dos sujeitos envolvidos.

\section{REFERÊNCIAS}

ARAÚJO, José Carlos Souza. Para uma análise das representações sobre as técnicas de ensino. In: VEIGA, Ilma Passos Alencastro. (Org) Técnicas de ensino: por que não? Campinas: Papirus, 2011.

BAQUIM, Cristiane Aparecida. O sonho feminino de Ícaro: a educação das pioneiras da aviação militar brasileira na Academia da Força Aérea. 2008. Tese (Doutorado). Universidade Federal de São Carlos, São Carlos (SP), 2008.

FELDMANN, Marina Graziela et al. Formação docente e as mudanças na sala de aula: um diálogo complexo. Olhar de professor. Ponta Grossa, v. 7, n. 2, p. 143-158, 2004.

GIL, Antonio Carlos. Didática do Ensino Superior. São Paulo: Atlas, 2009.

KIRSCH, Deise Becker. Processos de ensinar e de aprender: os instrutores militares e os cadetes da Aeronáutica. 2013. 186 f. Tese (Doutorado em Educação) - Programa de Pós-Graduação em Educação, Universidade Federal de São Carlos, São Carlos, 2013.

KIRSCH, Deise Becker. MIZUKAMI, Maria da Graça Nicoletti. Concepções acerca dos processos de ensinar e de aprender em uma academia militar. Revista Eletrônica de Educação, v. 8, n. 3, p. 182-195, 2014.

LIBÂNEO, José Carlos. Didática. São Paulo: Cortez, 1994. 
LUDWIG, Antonio Carlos Will. Democracia e ensino militar. São Paulo: Cortez, 1998.

MIZUKAMI, Maria da Graça Nicoletti et al. Escola e aprendizagem da docência: processos de investigação e formação. São Carlos: EdUFSCAR, 2002.

MIZUKAMI, Maria da Graça Nicoletti. Aprendizagem da docência: algumas contribuições de L.S. Shulman. Revista Centro de Educação, Santa Maria, v. 29, n.2, p. 33-49, 2004.

PIMENTA, Selma Garrido. ANASTASIOU, Léa das Graças Camargos. Docência no ensino superior. Coleção Docência em Formação. 5. ed. São Paulo: Cortez, 2011.

SANTOS, Sydione. Processos formativos e reflexivos: contribuições para o desenvolvimento profissional de professores. 2008. Tese (Doutorado) - Universidade Federal de São Carlos, São Carlos (SP), 2008.

SAVIANI, Dermeval. Escola e democracia: teorias da educação. São Paulo: Cortez, 1986.

SHULMAN, Lee. Teaching as community property: essays on higher education. Jossey Bass, 2004.

SHULMAN, Lee. Conocimiento y enseñanza: fundamentos de la nueva reforma. Granada (Esp). Profesorado: Revista de curriculum y formación del profesorado, v.9, n.2, 2005. Disponível em: <http://www.ugr.es/ recfpro/rev92ART1.pdf>. Acesso: 15 out. 2011.

TARDIF, Maurice. Saberes docentes e formação profissional. 3. ed. Petrópolis: Vozes, 2002.

TARDIF, Maurice. LESSARD, Claude. O trabalho docente: elementos para uma teoria da docência como profissão de interações humanas. Petrópolis: Vozes, 2009.

VEIGA, Ilma Passos Alencastro. Alternativas pedagógicas para a formação do professor da educação superior. In: VEIGA, Ilma Passos Alencastro. VIANA, Cleide Maria Quevedo Quixadá (orgs.) Docentes para a educação superior: processos formativos. Campinas: Papirus, 2010.

VEIGA, Ilma Passos Alencastro. A docência na Educação Superior e as didáticas especiais: campos em construção. Revista Centro de Educação. Dossiê: docência na educação superior. Universidade Federal de Santa Maria. v.36, n.3, set./dez. 2011 a.

VEIGA, Ilma Passos Alencastro. (org.) Técnicas de ensino: por que não? Campinas, SP: Papirus, 2011b.

ZABALA, Antoni. A prática educativa: como ensinar. Porto Alegre: Artmed, 1998. 